\title{
ОЦЕНКА ВЛИЯНИЯ РАННЕЙ КОРРЕКЦИИ ГИПЕРГЛИКЕМИИ НА ДИНАМИКУ ВЕСА, ИНСУЛИНОРЕЗИСТЕНТНОСТЬ У ЛИЦ СТАРШЕ 45 ЛЕТ С НАРУШЕННОЙ ТОЛЕРАНТНОСТЬЮ К ГЛЮКОЗЕ
}

\author{
Андреева Н.В.
}

\author{
ГБУз «Консультативно-диагностический чентр №6 ДЗМ», Москва
}

ЦЕЛЬ: оценить влияние ранней коррекции гипергликемии на динамику веса, уровень инсулинорезистентности, частоту развития сахарного диабета у лиц старше 45 лет с нарушенной толерантностью к глюкозе (НТГ), получающих метформин-лонг.

МАТЕРИАЛЫ И МЕТОДЫ: в исследование включены 58 пациентов (40 женщин 68,9\% и 18 мужчины 31,1\%) в возрасте 45-70 лет (медиана (Ме) - 57,5 лет), которые были разделены на 3 группы: 1группа (10 чел) с повышенным ИМТ (25-30); 2группа (16)- ожирение 1степени(30-34,9); Згруппа (32) - с ожирением 2 степени (ИМТ 35,0-39,9). Наследственность у всех пациентов была отягощена, причем по 1-й линии родства. Диагноз подтвержден результатами проведенного орального глюкозотолерантного теста, показателей инсулина, с-пептида в крови. Все пациенты получали терапию метформин-лонг в дозе 1000 мг на ночь в течение года. Пациенты были обучены правилам рационального питания (в рамках обучения в школе диабета). Проводилась оценка уровня целевых показателей гликемии (глюкоза крови натощак, через 2 часа после приема пищи, гликированный гемоглобин), индекса массы тела (ИМТ), показатели уровня инсулина крови и с-пептида. Статистическая обработка проводилась в программе Statistica 7.0.

PEЗУЛЬТАТЫ: через 6 месяцев терапии у пациентов с избыточной массой тела помимо субъективного улучшения общего состояния, значительно улучшились клинико-метаболические показатели: нормализировались уровни с-пептида и инсулина у $89 \%(<0,001)$ пациентов, ИМТ уменьшился на 9,5\% $(p<0,05)$, уровень $\mathrm{HbA}_{1 с}$ составил 94,5\%. В группе с ожирением 1 степени целевые показатели гликемии достигнуты у 67\%, уровень $\mathrm{HbA}_{1 с}$ составил 5,5-5,9\% у 92,5\% пациентов, масса тела снизилась (ИМТ уменьшился на $11,7 \%$ ( $<0,05)$, уровень нормализации инсулина крови, с-пептида составил 76,9\%. У лиц с ожирением 2 степени наблюдается наименьшее достижение нормальных значение с-пептида, инсулина крови 53,5 и 66,8\% соответственно; уровень $\mathrm{HbA}_{1 с}$ составил 77,9\%, вес пациентов снизился на 2,5\%(p<0,05). Через год терапии наблюдается в 1 группе удержание веса в 93,7\%. Также уровни с-пептида, инсулина крови остались стабильно нормальными у 93,4\% пациентов. Уровень $\mathrm{HbA}_{1 c}$ 5,6-5.9\% в 98,8\% случаев. Во 2-й группе на фоне регулярного приема метформина-лонг вес снизился на 9,2\% ( $<<0,05)$, с-пептид и инсулин остался в пределах нормы в 63,5\%(<0,001), масса тела снизилась на $14,2 \% 89 \%(p<0,05)$, уровень НbА в пределах нормы у 76,9\% пациентов, у 16,85\% - повысился до 6,4\% (до уровня предиабет) и у 1 пациента (6,25\%) диагностирован сахарный диабет $\mathrm{HbA}_{1 с}$ составил 6,5\%. У лиц с ожирением 2 степени наблюдались достижение нормальных значение с-пептида, инсулина крови 37,8 и 51,3\% соответственно, снижение веса ИМТ на 5,4\%; целевые показатели гликемии статистически значимо не изменились, вес пациентов снизился на 7,8\%(p<0,05), уровень $\mathrm{HbA}_{1 с}$ оставался в пределах нормы у $61,7 \%$ пациентов, у 28,9\% — повысился до 6,4\% (до уровня предиабет), у 3 пациентов выявили сахарный диабет - 9,37\%

Выводы: назначение адекватной дозы препарата метформин-лонг способствует достижению целевых показателей гликемии, нормализации уровня с-пепида и инсулина у пациентов с повышенным и и избыточным весом 1 степени более эффективнопо сравнению с пациентами с ожирением 2 степени, замедляет развитие сахарного диабета 2 типа у лиц с ожирением 1 степени в 6,5\% и 2 степени в 9,4\% случаях.

КЛЮЧЕВЫЕ СЛОВА: ожирение; нарушенная толерантность к глюкозе; C-пептид; инсулин крови; сахарный диабет 2 типа; гликированный гемоглобин. 